\title{
EIJEST
}

\section{AN INTEGRATED APPROACH FOR MULTI-OBJECTIVE PRODUCTION AND DISTRIBUTION PLANNING IN SUPPLY CHAIN MANAGEMENT*}

\author{
Mohamed A. El-baz ${ }^{1}$ and Yehya. I. Mesalam ${ }^{+}$ \\ Industrial Eng. Dept., Zagazig University, Zagazig, Egypt
}

\begin{abstract}
In real world, supply chain works as interrelating network of suppliers, manufacturers, distributers, and customers to satisfy customer satisfaction. Because of the nature of the conflicting objective functions that affect the performance of supply chain management, coordinate all phases of supply chain as a whole should be considered. This paper presents the solutions for integrated production and distribution planning problem and investigates the effectiveness of their integration through a computational study. The environment is a multi-plant, multi-retailers, multi-item and multi-period where the objective functions are total cost, delivery time, and quality. The model is implemented using Fuzzy Linear Programming (FLP), Goal Programming (GP), and Fuzzy Goal Programming (FGP) approaches. The results obtained by using lingo 11.0 software show that the proposed FGP provides high quality solution as well as the effectiveness of the integrated model over the decoupled one.
\end{abstract}

KEY WORDS: supply chain, production distribution planning, multi-objective, integrated approach, fuzzy goal programming.

\section{UNE APPROCHE INTÉGRÉE POUR PLUSIEURS OBJECTIF DE PRODUCTION ET}

\section{PLANIFICATION DE LA DISTRIBUTION EN SUPPLY CHAIN MANAGEMENT}

RÉSUMÉ

Dans le monde réel, chaîne d'approvisionnement fonctionne comme un réseau interrelation des fournisseurs, fabricants, distributeurs et clients à satisfaire la satisfaction du client. En raison de la nature des fonctions objectives contradictoires qui affectent les performances de la gestion de chaîne d'approvisionnement, de coordonner toutes les phases de la chaîne logistique dans son ensemble doit être envisagée. Ce document présente les solutions pour la production intégrée et problème de planification de distribution et examine l'efficacité de leur intégration à travers une étude computationnelle. L'environnement est un multi-site, multi-détaillants multi-point et multi-période où les fonctions objectives sont le coût total, délai de livraison et de qualité. Le modèle est implémenté en utilisant Fuzzy Programmation Linéaire (FLP), la programmation Objectif (GP) et Fuzzy Goal Programming (FGP) approches. Les résultats obtenus en utilisant le logiciel montrent que le jargon de 11,0 FGP proposé offre une solution de haute qualité ainsi que l'efficacité du modèle intégré sur le découplage.

MOTS CLES: chaîne d'approvisionnement, planification de la distribution de production, multi-objectifs, l'approche intégrée, la programmation objective floue.

\footnotetext{
* Received: 14/8/2011, Accepted: 11/9/2011 (Original Paper)

+ Contact Author (e-mail: ymesalam@yahoo.com)

1 Alternative author (e-mail: elbaz@mail2world.com )
} 


\section{El-baz and Mesalam}

\section{INTRODUCTION}

Supply chain management (SCM) has been a hot topic in the management arena in the recent years. The term "supply chain" (SC) conjures up images of products, or supplies, moving from manufacturers to distributors to retailers to customers, along a chain, in order to fulfill a customer request (Gong et al. 2008). SCM explicitly recognizes interdependencies and requires effective relationship management between chains. The challenge in global SCM is the development of decision-making frameworks that accommodate diverse concerns of multiple entities across the supply chain. Considerable efforts have been expended in developing decision models for SC problems (Narasimhan and Mahapatra, 2004).

Enterprises have to satisfy customers with a high service level during standing high transportation, raw material and distribution costs. In traditional SCs, purchasing, production, distribution, planning and other logistics functions are handled independently by decision makers although SCs have different objectives. To overcome global risks in related markets, decision makers are obliged to fix a mechanism which different objective functions (minimizing transportation/production, backorder, holding, purchasing costs and maximizing profit and customer service level etc.) can be integrated together.

SCs performance measures are categorized as qualitative and quantitative. Customer satisfaction, flexibility, and effective risk management belong to qualitative performance measures. Quantitative performance measures are also categorized by:

(1) objectives that are based directly on cost or profit such as cost minimization, sales maximization, profit maximization, etc. and

(2) objectives that are based on some measure of customer responsiveness such as fill rate maximization, customer response time minimization, lead time minimization, etc (Altiparmak et al., 2006). However, the SCM design and planning is usually involving trade-offs among different goals.

In this study, we developed a Mixed Integer Linear Programming model (MILP) to design and optimize a supply chain network via providing multi objective functions mentioned above together. We considered three objectives for SCM problem:
(1) Minimization of total costs.

(2) Maximize the utilization level of facilities.

(3) Minimization of total delivery time.

The following details the organization of the remainder of this paper. Section 2 is dedicated to a review of the literature. Section 3 describes the proposed fuzzy model. Section 4 develops the mathematical model and the decoupled one and the integrated model. Section 5 presents an illustrative case study for implementing the feasibility of applying the proposed approach. Finally, Section 6 presents the conclusions and recommendations.

\section{LITERATURE REVIEW}

In real-world situations, most enterprises have only paid attention on separately optimizing their production/distribution planning decisions, but using these decisions prevent possible improvement in decision effectiveness. Hence, the issues of how to simultaneously integrate manufacturing and distribution systems in a supply chain with multi objectives have attracted considerable interest from both practitioners and academics (Liang and Cheng, 2009). Literature review presents a review about supply chain modeling and fuzzy applications in SC planning, respectively. Haq et al. (1991) considered a single product, a three stages SC with one production facility and multi production steps, several warehouses, and several retailers. In 2002, Lee and Kim also developed almost similar model for production and distribution problem on SC structure. The model addressed problem of multi shop production which produced different products, with stack buffers to temporarily store the product, and intermediate warehouses and retailers. Both researches determined the quantity produced at each production stage, quantity transported from each stage to the next stage of SC, and inventory level at all SC stages, but with different formulation. Furthermore, Haq et al. (1991) also considered realistic condition during model development, such as setup time, production lead time, distribution lead time, losses during production and distribution, recycling of production losses, and backlogging. In other paper, Barbarosoglu and Ozgur (1999) considered a three stages SC, a single plant producing multiple products which are distributed to several depots and delivered from depots to customers. They formulated an integrated model to determine the quantity produced and quantity transported from plant to depot, quantity transported from depot to customer, and inventory 
level at each plant and depot. In a multi-plant production system with several product items, the assignment of productions to plants determines the production performance. Moreover, in such a production system with scattered customers the assignment of plants to customers for distribution determines the performance of distribution. Integration of these two functions may lead to a substantial saving in global costs and to an improvement in relevant service by exploiting scale economies of production and transportation, balancing production lots and vehicle loads, and reducing total inventory and stock out (Fumero and Vercellis 1999). Martin et al. (1993) and Thomas and Griffin (1996) provided evidence of the potential economic benefits derived from an integration of production and distribution planning. Cohen and Lee (1989) present a deterministic, mixed integer, non-linear programming with economic order quantity technique to develop a global supply chain plan. Output of the model provides global resource deployment policy for the plants, distribution centers and customer zones. Pyke and Cohen (1993) develop a mathematical programming model by using stochastic sub-models to design an integrated supply chain that involves manufacturers, warehouses and retailers. Due to not considering multiple products and having only one plant, one warehouse and one retailer, the model fails to represent the complicated supply chain networks of the real world. Ozdamar and Yazgac (1997) develop a distribution/production system that involves a manufacturer center and its warehouses. The paper tries to minimize total costs such as inventory; transportation costs etc. under production capacity and inventory equilibrium constraints. Syarif et al. (2002) propose new algorithm based genetic algorithm to design a multi stage supply chain distribution network under capacity constraints for each echelon. Although experimental results show that the proposed algorithm can give better heuristic solutions than traditional genetic algorithm, the comparison with the performances of other meta-heuristic techniques (tabu search, simulated annealing etc.) are remained unanswered. Yan et al. (2003) try to contrive a network which involves suppliers, manufacturers, distribution centers and customers via a mixed integer programming under logic and material requirements constraints. Chen and Lee (2004) develop a multi-product, multi-stage, and multi-period scheduling model to deal with multiple incommensurable goals for a multi-echelon supply chain network with uncertain market demands and product prices. The supply chain scheduling model is constructed as a mixed-integer nonlinear programming problem to satisfy several conflict objectives, such as fair profit distribution among all participants, safe inventory levels, maximum customer service levels, and robustness of decision to uncertain product demands, therein the compromised preference levels on product prices from the sellers and buyers point of view are simultaneously taken into account. Gen and Syarif (2005) deal with a production/distribution problem to determine an efficient integration of production, distribution and inventory system in order to minimize system wide costs while satisfying all demand required. The study proposes a new technique called spanning tree-based genetic algorithm. In order to improve its efficiency, the proposed method is hybridized with the fuzzy logic controller concept for auto-tuning the genetic algorithm parameters. The proposed method is compared with traditional spanning tree-based genetic algorithm approach. This comparison shows that the proposed method gives better results. Lin et al. (2007) compare flexible supply chains and traditional supply chains with a hybrid genetic algorithm and mention advantages of flexible ones. Azaron et al. (2008) develop a multi-objective stochastic programming approach for supply chain design under uncertainty. Demands, supplies, processing, transportation, shortage and capacity expansion costs are all considered as the uncertain parameters.

In most real-world SCM problems, environment coefficients and model parameters are frequently imprecise / fuzzy because some information is incomplete and/or unavailable over the planning. Conventional LP and special solution algorithms cannot solve all fuzzy SCM problems. Fuzzy set theory was developed by Zadeh in 1965, since then fuzzy set theory has been applied to the fields of operations research (linear programming (LP), non-linear programming (NLP), multiple criteria decision making (MCDM) and so on), management science, artificial intelligence/expert system, statistics and many other fields. $\mathrm{Hu}$ and Fang (1999) solve the problem of fuzzy inequalities linear membership function by employing the concepts of constraint surrogating and maximum entropy. Vasant et al. (2005) propose a new fuzzy linear programming based methodology using modified S-curve membership function. Liang (2006) develops an interactive fuzzy multi-objective linear programming method for solving the fuzzy multi 


\section{El-baz and Mesalam}

objective transportation problems with piecewise linear membership function. Peidro et al. (2007) propose a new mathematical programming model for supply chain planning under supply, process and demand uncertainty. Chang (2007) proposes a new idea of how to formulate the binary piecewise linear membership function. Alves and Climaco (2007) review interactive methods for multi objective integer and mixed integer programming. Liang (2008) develops a Fuzzy Multi-Objective Linear Programming (FMOLP) model with piecewise linear membership function to solve integrated multi-product and multi-time period production/distribution planning decisions problems with fuzzy objectives. Liang and Cheng (2009) apply fuzzy sets to multi-objective manufacturing/distribution planning decision problems with multi-product and multi-time period in supply chains by considering time value of money for each of the operating categories. Peidro et al. (2009) propose a fuzzy mathematical programming model for supply chain planning which considers supply, demand and process uncertainties. The model has been formulated as a fuzzy mixed integer linear programming model where data are ill-known and modeled by triangular fuzzy numbers. Cao et al. (2010) develop stochastic chance constrained mixed-integer nonlinear programming models to solve the refinery short-term crude oil scheduling problem.

\section{PROPOSED MODEL}

Zeleny (1982) pointed out that programming has nothing to do with decision making when there is only a single objective, as decision making is already endowed in the estimation of the objective function value coefficient. Thus, when the objective function coefficient is determined the decision maker can only accept or discard the outcome resolved by the model, and no other information can ever be obtained from the model by the decision maker. The main aim of MOP is to find a feasible non-inferior solution set or compromise solution so that the decision maker can effectively focus on the trade-offs when several objectives are in conflict. as follows:

$$
\begin{aligned}
& \max \boldsymbol{f}=\left[f_{1}(\boldsymbol{x}), f_{2}(\boldsymbol{x}), \ldots, f_{k}(\boldsymbol{x})\right] \\
& \text { s.t: } \quad \boldsymbol{A} \boldsymbol{x} \leq \boldsymbol{b} \\
& \boldsymbol{x} \geq \mathbf{0}
\end{aligned}
$$

where, $\boldsymbol{b}=\left[b_{1}, b_{2}, \ldots, b_{m}\right]^{T}, \boldsymbol{x}=\left[x_{1}, x_{2}, \ldots, x_{n}\right]^{T}$,

$$
\boldsymbol{A}=A_{m \times n}
$$

\subsection{Fuzzy Linear Programming}

Bellman and Zadeh (1970) applied the notion of fuzzy sets for decision making theory, considering conflicts between constraint equation and objective equation of the general programming, and proposed the max-min operation method in order to determine the optimal decision of the two solutions. Furthermore, Tanaka et al. (1974) advanced fuzzy mathematics programming (FMP), which resulted in the widespread application of FMP on several practical levels.

Zimmermann first introduced fuzzy set theory into the conventional linear programming problem in 1976, and combined the fuzzy linear programming (FLP) model with MOP into fuzzy multi-objective linear programming (FMOLP) (Zimmermann, 1978). The FLP employed in this study uses the max-min-operation method, which turns multiple objectives into a single one as following:-

(a) Determination of the ceiling and bottom limit of each of the objectives and constraint equations

If it is assumed that the decision maker has the most satisfactory and ideal ceiling limit value $f_{i}^{*}(\boldsymbol{x})$ and the bottom limit value $f_{i}^{-}(\boldsymbol{x})$ toward the $i$ th objective $f_{i}(\boldsymbol{x})$, then the decision maker can decide the values of the ceiling and bottom limit according to individual preference. Or the decision maker can take such objective as the function of the feasible solution space and find out the values through calculation, which is as shown in the payoff table.

(b) Establishment of membership function

The membership function toward the $i$ th fuzzy objective is as follows:

In case of maximize objective function

$$
\mu_{G_{i}}(\mathbf{x})=\left\{\begin{array}{ll}
0 & f_{i}(\mathbf{x}) \leq f_{i}^{-}(\mathbf{x}) \\
\frac{f_{i}(\mathbf{x})-f_{i}^{-}(\mathbf{x})}{f_{i}^{*}(\mathbf{x})-f_{i}^{-}(\mathbf{x})} & f_{i}^{-}(\mathbf{x}) \leq f_{i}(\mathbf{x}) \leq f_{i}^{*}(\mathbf{x}) \\
1 & f_{i}(\mathbf{x}) \geq f_{i}^{*}(\mathbf{x})
\end{array}\right\}
$$

In case of minimize objective function it will be 
$\mu_{G_{i}}(\mathbf{x})=\left\{\begin{array}{ll}0 & f_{i}(\mathbf{x}) \geq f_{i}^{*}(\mathbf{x}) \\ \frac{f_{i}(\mathbf{x})-f_{i}^{-}(\mathbf{x})}{f_{i}^{*}(\mathbf{x})-f_{i}^{-}(\mathbf{x})} & f_{i}^{*}(\mathbf{x}) \leq f_{i}(\mathbf{x}) \leq f_{i}^{-}(\mathbf{x}) \\ 1 & f_{i}(\mathbf{x}) \leq f_{i}^{-}(\mathbf{x})\end{array}\right\}$

as shown in Fig. 1.
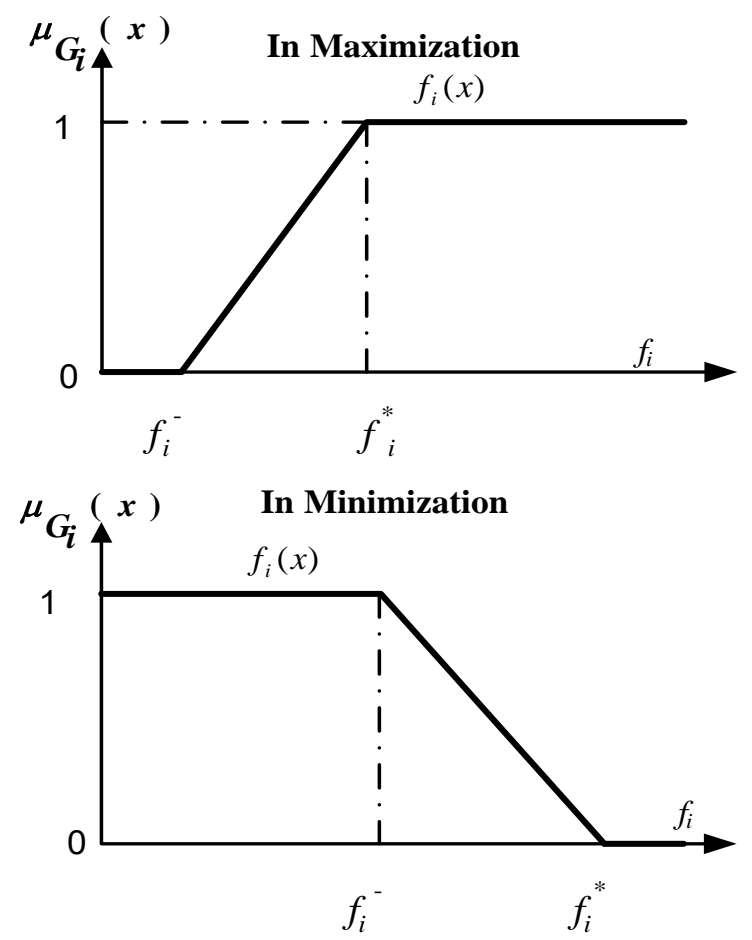

Fig. (1): Linear Membership Function of the Objective

(c) Set up the membership function for the decision making set $\mu_{D}(\boldsymbol{x})$

$$
\mu_{D}\left(\boldsymbol{x}^{*}\right)=\min _{i, j}\left\{\mu_{G_{i}}(\boldsymbol{x}), i=1, \ldots, k\right\}
$$

From the max-min operation equation, the feasible fuzzy set can be found at the intersection of the objective and constraint equation. Since the decision maker needs precise decision-making recommendations, the maximum value of the membership in this decision making set is required. As a result, the maximum is utilized, and the corresponding membership function is thus obtained.

$$
\left.\begin{array}{rl}
\mu_{D}\left(\boldsymbol{x}^{*}\right) & =\max \min \left\{\mu_{G_{i}}\left(\boldsymbol{x}^{*}\right), i=1, \ldots, k\right\} \\
& \geq \max \min \left\{\mu_{G_{i}}(\boldsymbol{x}), i=1, \ldots, k\right\}
\end{array}\right\}
$$

(d) Turn the multiple objectives into a single objective for resolution

Finally, this problem can be transformed into precise LP problem for resolution: $\max \lambda$

subject to:

$$
\begin{aligned}
& {\left[\frac{f_{i}(\boldsymbol{x})-f_{i}^{-}(\boldsymbol{x})}{f_{i}^{*}(\boldsymbol{x})-f_{i}^{-}(\boldsymbol{x})}\right] \geq \lambda, i=1, \ldots, k} \\
& \boldsymbol{A} \boldsymbol{x} \leq \boldsymbol{b} \\
& \boldsymbol{x} \geq \mathbf{0}
\end{aligned}
$$

Thus, general linear programming can be used for resolution.

The procedures of the opera

(3) follows:

The upper bound and lower 1 of each objective and constraint equation are aetermined and multiple objectives are turned into a single objective for solving the maximal achievement level $\lambda$. $\max \lambda$

subject to:

$$
\begin{aligned}
\lambda \leq & \frac{f_{i}(\boldsymbol{x})-f_{i}^{-}}{f_{i}^{*}-f_{i}^{-}}, \quad i=1,2, \ldots, k \\
& \boldsymbol{A x} \leq \boldsymbol{b} \\
& \boldsymbol{x} \geq \mathbf{0}
\end{aligned}
$$

\section{2 fuzzy goal programming FGP.}

Generally, the FGP model will be formulated such as:

$$
\text { Opt } \sum_{i=1}^{n}\left(d_{i}^{+}+d_{i}^{-}\right)
$$

subject to.

$$
\begin{aligned}
& \lambda_{i}+d_{i}^{-}-d_{i}^{+}=1 \quad i=1,2,3, \ldots, n \\
& A X \leq b \\
& d_{i}^{-} \geq 0 ; d_{i}^{+} \geq 0 ; d_{i}^{-} * d_{1}^{+}=0 ; \quad X \geq 0
\end{aligned}
$$

\section{MODEL FORMULATION}

The problem considered here consists of a number of suppliers which supply manufactures with raw materials, plants which produce multiple items with a limited capacity over time, distribution centers which receive finished products from plants and store excess production, and retailers which responsible for distribution the products. For each product type, it is necessary to incur a fixed setup cost on a lot for lot basis, not dependent on the realized volume, which captures the setup cost for the whole plant. The manufactured products are directly delivered to distribution centers (DCs). The firm owns the manufacturing plants, DCs, and retail outlets. Therefore, the manufacturers are responsible for the sales of their products in the retail outlets. The movement of a vehicle incurs a fixed cost related to vehicle depreciation and insurance, cost of capital, order cost, and driver wages, and a 


\section{El-baz and Mesalam}

variable transportation cost dependent on transported item, its quantity, and traveled path. It is assumed that the firm can change the fleet size freely without extra cost. The demand for an item in a period at a retail outlet is expressed as stochastic demand. It is assumed that the demands are variation and not fixed. The unsatisfied demand at the retail outlet is considered as stock out. Fig. 2 shows the concepts of supply chain network.

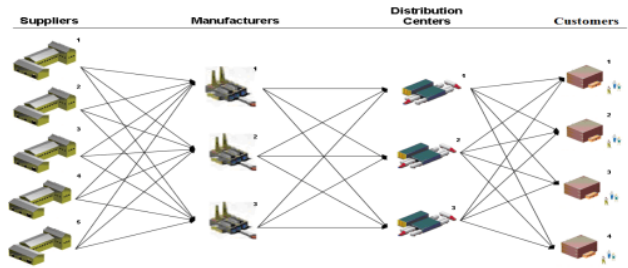

Fig. (2): Concepts of Supply-Chain

In this paper, we develop an integrated production and distribution model for multiple plants on which each plant produces some specific products. Considering the high cost of distribution and varied vehicle types, we also include vehicle characteristics such as delivery cost, load capacity and travel time to determine the quantity delivered from plant to distribution centre (DC) and the number of direct shipment trip for each vehicle. we develop a decoupled model and compare the solution of the two models to determine the value of coordinating production and distribution functions.

\subsection{Integrated Production Distribution Model Construction}

Definitions of Symbols are presented at Appendix I.

\subsubsection{Minimize total cost for supply chain}

Min total cost $=$ production cost during ordinary working hours + transportation cost for product from factory to DCs and from DCs to retailers + inventory cost from suppliers to factory, factory to DCs and from DCs to retailers + shortage cost of product.

$$
\begin{aligned}
& \text { Min }=\sum_{i} \sum_{j} c_{i j} \sum_{t} x_{i j t}+\sum_{i} \sum_{j} s_{i j} \sum_{t} y_{i j t}+ \\
& \sum_{j} \sum_{l} h_{i j}^{R} \sum_{t} I_{i j t}^{R}+\sum_{i} \sum_{j} h_{i j}^{p} \sum_{t} I_{i j t}^{p}+\sum_{j} \sum_{k} h_{j k}^{d} \sum_{t} I_{j k t}^{d} \\
& +\sum_{j} \sum_{l} h_{j l}^{r} \sum_{t} I_{j l t}^{r}+g \sum_{i} \sum_{k} \sum_{t} z_{i k t}^{d}+g \sum_{k} \sum_{l} \sum_{t} z_{k l t}^{r} \\
& +\sum_{i} \sum_{j} \sum_{t} g_{i} y_{i j t}+\sum_{i} \sum_{j} \sum_{k} d_{i j k}^{d} \sum_{t} q_{i j k t}+ \\
& \sum_{j} \sum_{k} \sum_{l} d_{j k l}^{r} \sum_{t} f_{j k l t}+\sum_{s} \sum_{i} \sum_{j} t_{s i j t} R_{s i j t}
\end{aligned}
$$

\subsubsection{Maximize the utilization level of facilities}

Capacity utilization can be measured in percentage of actual output or in the percentage of time a constrained resource is used. This study uses time-based measurement. Specifically, capacity utilization is measured as the percentage of time of a machine spent in productive and nonproductive uses. Capacity usage is tracked on a monthly basis. Productive use is the actual running time of a machine and does not include time when the machine is idle, breaking-down or getting setups for production lots. Nonproductive use is the time a machine spends in waiting, breakdown, repair and maintenance, getting setups and performing tool tests. Then facilities utilization can be calculated as

$$
\operatorname{Max} W_{t}=1-\left[\left(\sum_{i} \sum_{j} \sum_{t}^{\prime} o_{i j} * x_{i j t}\right) / L_{i}\right]
$$

\subsubsection{Minimization of total delivery time}

$\operatorname{Min} f_{3}=\sum_{i} \sum_{j} \sum_{k} \sum_{t} \frac{u_{i j k t}+U_{i j} \cdot y_{i j t}+o_{i j}}{B_{i j k t}} f_{j k l t}$

\subsection{Model Constraints}

The first constraint (11) is the capacity restriction on production capacity at a plant.

$\sum_{j} o_{i j} x_{i j t}+\sum_{j} u_{i j} y_{i j t} \leq L_{i} \quad \forall i, t$

The second constraint (12) is used to force the 
binary set-up variables. The parameter $M$ is a sufficiently large positive number.

$x_{i j t} \leq M \cdot y_{i j t} \quad \forall i, j, t$

Constraints (13 - 16) assure the inventory balance in periods at a plant, DCs, and retailer.

$$
\begin{aligned}
& I_{i j t-1}^{R}+\sum_{s} R_{s i j t}-x_{i j t}=I_{i j t}^{R} \quad \forall i, j, t \\
& I_{i j t-1}^{p}+x_{i j t}-\sum_{k} q_{i j k t}=I_{i j t}^{p} \quad \forall i, j, t \\
& I_{j k t-1}^{d}+\sum_{i} q_{i j k t}-\sum_{l} f_{j k l t}=I_{j k t}^{d} \quad \forall j, k, t \\
& I_{j l t-1}^{r}+\sum_{k} f_{j k l t}-E_{j l t}=I_{j l t}^{r} \quad \forall j, l, t
\end{aligned}
$$

Constraint (17) assures that the actual demand for any item at a retail outlet in any period cannot exceed the forecasted demand in that period.

$$
I_{j l t-1}^{r}+\sum_{k} f_{j k l t}-I_{j k t}^{r} \geq \mathrm{E}_{\mathrm{jlt}} \forall j, l, t
$$

Constraints $(18-20)$ represent the restriction on storage capacity at plants, DCs, and a retail outlet.

$$
\begin{aligned}
& \sum_{i} I_{i j t}^{R} \leq W_{i}^{R} \quad \forall i, t \\
& \sum_{i} I_{j k t}^{d} \leq W_{k}^{d} \quad \forall k, t \\
& \sum_{i} I_{j l t}^{r} \leq W_{l}^{r} \quad \forall l, t
\end{aligned}
$$

Constraints $(21-22)$ determine the number of vehicles required for a delivery.

$$
\begin{aligned}
& z_{i k t}^{d} \geq \sum_{j} \frac{q_{i j k t}}{B_{i j k t}} \quad \forall i, k, t \\
& z_{k l t}^{r} \geq \sum_{j} \frac{f_{j k l t}}{B_{i j k t}} \quad \forall k, l, t
\end{aligned}
$$

Constraint (23) describes the raw material restriction.

$\sum_{i} R_{s i j t} \leq \sup _{s} \quad \forall s, t$

Constraint (24) gives the supplier capacity. $\sum_{i} u_{r j} X_{i j t} \leq \sum_{s} R_{s i j t} \quad \forall j, r, t$

Constraints (25 - 26) give the production capacity constraint.

$\sum_{j} X_{i j t} \leq D_{i} \quad \forall i, t$

$\sum_{j} x_{i j t} \leq \sum_{\mathrm{j}} \sum_{\mathrm{k}} q_{i j k t} \quad \forall i, t$

Constrain (27) expresses the initial inventory levels at both plants and retail outlets.

$I_{i j 0}^{R}=0, I_{j k 0}^{d}=0, I_{j l 0}^{r}=0 \quad \forall i, j, t$

Constraint (28) enforces the restrictions of nonnegativity, integer, and binary nature on the decision variables.

$x_{i k t} \geq 0, q_{i j k t} \geq 0, f_{j k l t} \geq 0, Q_{j l t} \geq 0$,

$I_{i k t}^{d} \geq 0, I_{j k t}^{r} \geq 0, z_{i k t}^{d} \geq 0, z_{k l t}^{r} \geq 0, y_{i k t} \in\{0,1\}$

And all are integer for $\mathrm{i}, \mathrm{j}, \mathrm{k}, \mathrm{t}$.

\subsection{Decoupled Production Distribution Model}

The classical decoupled approach is sometimes defined as two-phase procedure. In the first phase, we determined the production plan to meet total aggregate demand over all DCs per period. Based on this plan, we determined the delivery plan in the second phase.

\section{Phase 1: Production Planning Problem (P1)}

The first phase determines the types of products to be produced at each plant, production and inventory quantity for each product which minimizes the cost of setup, and production and inventory level at all plants.

The MIP formulation of production planning model (P1) as follows: 


\section{El-baz and Mesalam}

$\operatorname{Min}=\sum_{i} \sum_{j} c_{i j} \sum_{t} x_{i j t}+\sum_{i} \sum_{j} s_{i j} \sum_{t} y_{i j t}+$

$\sum_{j} \sum_{l} h_{i j}^{R} \sum_{t} I_{i j t}^{R}+\sum_{i} \sum_{j} h_{i j}^{p} \sum_{t} I_{i j t}^{p}+$

$\sum_{i} \sum_{j} \sum_{t} g_{i} y_{i j t}+\sum_{s} \sum_{i} \sum_{j} t_{s i j t} R_{s i j t}$

$\operatorname{Max} W_{t}=1-\left[\left(\sum_{i} \sum_{j} \sum_{t} o_{i j} * x_{i j t}\right) / L_{i}\right]$

$\operatorname{Min} f_{3}=\sum_{i} \sum_{j} \sum_{k} \sum_{t} \frac{u_{i j} \cdot y_{i j t}+o_{i j}}{B_{i j k t}} x_{i j t}$

Subject to

Equation (11), (12), (13), (14), (23), (24), (25) and (28).

Phase 2: Distribution Planning Problem (P2)

$$
\begin{aligned}
& \operatorname{Min}=\sum_{j} \sum_{k} h_{j k}^{d} \sum_{t} I_{j k t}^{d}+\sum_{j} \sum_{l} h_{j l}^{r} \sum_{t} I_{j l t}^{r}+ \\
& g \sum_{i} \sum_{k} \sum_{t} z_{i k t}^{d}+g \sum_{k} \sum_{l} \sum_{t} z_{k l t}^{r}+ \\
& \sum_{i} \sum_{j} \sum_{k} d_{i j k}^{d} \sum_{t} q_{i j k t}+\sum_{j} \sum_{k} \sum_{l} d_{j k l}^{r} \sum_{t} f_{j k l t} \\
& \operatorname{Max} W_{t}=1-\left[\left(\sum_{i} \sum_{i} \sum_{t} o_{i j} * x_{i j t}\right) / L_{i}\right] \\
& \operatorname{Min} f_{3}=\sum_{i} \sum_{i} \sum_{k} \sum_{t} \frac{u_{i j k t}+U_{i j} \cdot y_{i j t}+o_{i j}}{B_{i i k t}} f_{j k l t}
\end{aligned}
$$

Subject to

Equation (15), (16), (17), (18), (19), (20), (21), (22), (26), (27) and (28).

\section{EMPIRICAL CASE AS ILLUSTRATIVE CASE STUDY}

We conducted numerical experiment to implement the integrated and decoupled model for Production Distribution problems. The data sets were randomly generated using different problem parameters. Table 1 shows the configuration of test problems. First, fifteen different sized problems solved using FLP, GP, and FGP models for each of the integrated and decoupled planning approaches in order to evaluate the electiveness of the integrated planning approach against the decoupled one. The lingo 11.0 software used to solve the fuzzy linear programming and proposed fuzzy goal programming models. The customers demand is generated from a uniform distribution on $[75,110]$. Capacity of all vehicles is set to 100 units. Production capacity is equal to the average demand for each plant multiplied unit processing time plus the set up time. Unit processing cost is randomly chosen from a uniform distribution on $[15,25]$. For the cost setup, holding at plant, distribution and retailer outlet $s_{i j}=200 c_{i j}, h^{p_{i j}}=$ $0.25 \mathrm{c}_{\mathrm{ij}}, \mathrm{h}_{\mathrm{ij}}^{\mathrm{d}}=0.1 \mathrm{c}_{\mathrm{ij}}$, and $\mathrm{h}_{\mathrm{ij}}^{\mathrm{r}}=0.15 \mathrm{c}_{\mathrm{ij}}$ are assigned respectively. Unit transportation cost is set to the value between 1.0 and 3.0 in proportion to the Euclidean distance between to location. Coordinates of plants and DCs, DCs and retailer outlets are randomly generated from a uniform distribution on $[0,100]$, Fixed vehicle cost is set to 500. Unit processing time is randomly generated from a uniform distribution on $[5,15]$. Setup time is determined by $50 * \mathrm{o}_{\mathrm{ij} .}$.

\subsection{Results and Analysis}

The paper demonstrates how to design a SCN for the product to determine not only the subset of plants and DCs to be opened, but also the distribution strategy that will satisfy the demand imposed by customers in a cost-effective and timely manner under an all capacities constraint. 
However, in the supply chain network design problem, it is hard to describe these problem parameters as known variables because there are not sufficient enough data to analyze. Table 2 shows the output solution for the integrated test problems using FGP, GP and FLP. Also Table 3 shows the output solution for the decoupled test problems using FGP, GP and FLP. Table 4 shows that the integrated planning produced higher demand fill rate than the decoupled one with average $2.55 \%$, which indicates the improved customer service. Demand fill rate is computed by $100^{*}$ (total received quantities at retail outlets/total forecasted demand at retail outlets).

Table (1): shows the configuration of test problems

\begin{tabular}{|c|c|c|c|c|c|c||}
\hline $\begin{array}{c}\text { Problem } \\
\text { name }\end{array}$ & $\begin{array}{c}\text { No. of } \\
\text { suppliers } \\
\text { (S) }\end{array}$ & $\begin{array}{c}\text { No. of } \\
\text { plants } \\
(\mathbf{I})\end{array}$ & $\begin{array}{c}\text { No of } \\
\text { distribution } \\
\text { centers( K) }\end{array}$ & $\begin{array}{c}\text { No. of } \\
\text { retailers } \\
(\mathbf{L})\end{array}$ & $\begin{array}{c}\text { No. of } \\
\text { products } \\
(\mathbf{J})\end{array}$ & $\begin{array}{c}\text { No. of time } \\
\text { periods (T) }\end{array}$ \\
\hline \hline P1 & 2 & 2 & 3 & 3 & 2 & 2 \\
\hline P2 & 2 & 3 & 4 & 4 & 3 & 2 \\
\hline P3 & 2 & 3 & 5 & 5 & 3 & 2 \\
\hline P4 & 2 & 3 & 5 & 6 & 3 & 3 \\
\hline P5 & 3 & 3 & 5 & 7 & 4 & 3 \\
\hline P6 & 3 & 4 & 6 & 8 & 4 & 4 \\
\hline P7 & 3 & 4 & 7 & 8 & 4 & 4 \\
\hline P8 & 3 & 5 & 7 & 9 & 5 & 5 \\
\hline P9 & 4 & 5 & 8 & 10 & 5 & 5 \\
\hline P10 & 4 & 5 & 9 & 10 & 5 & 6 \\
\hline P11 & 4 & 6 & 10 & 12 & 6 & 6 \\
\hline P12 & 5 & 6 & 10 & 12 & 6 & 7 \\
\hline P13 & 5 & 6 & 11 & 14 & 6 & 7 \\
\hline P14 & 5 & 6 & 12 & 16 & 6 & 7 \\
\hline P15 & 6 & 7 & 12 & 18 & 6 & 8 \\
\hline
\end{tabular}


AN INTEGRATED APPROACH FOR MULTI-OBJECTIVE PRODUCTION AND DISTRIBUTION PLANNING IN SUPPLY CHAIN MANAGEMENT

\section{El-baz and Mesalam}

Table (2): shows the output solution for the integrated test problems using FGP, GP and FLP

\begin{tabular}{|c||c|c|c||c|c|c||c|c|c||}
\hline \hline \multirow{2}{*}{ Prob. } & \multicolumn{3}{|c||}{ FGP } & \multicolumn{3}{|c||}{ GP } & \multicolumn{3}{|c||}{ FLP } \\
\cline { 2 - 10 } & Z1 & Z2 & Z3 & Z1 & Z2 & Z3 & Z1 & Z2 & Z3 \\
\hline \hline P1 & 383021.8 & 1356 & 0.85 & 383240.6 & 1374 & 0.80 & 383586.0 & 1389 & 0.78 \\
\hline P2 & 398971.1 & 1359 & 0.81 & 399269.5 & 1372 & 0.81 & 399710.6 & 1398 & 0.79 \\
\hline P3 & 499962.4 & 1370 & 0.80 & 500349.6 & 1382 & 0.76 & 500659.3 & 1394 & 0.70 \\
\hline P4 & 580176.5 & 1380 & 0.85 & 580400.5 & 1395 & 0.83 & 581170.9 & 1401 & 0.80 \\
\hline P5 & 740223.7 & 1402 & 0.93 & 740623.5 & 1420 & 0.88 & 740693.1 & 1432 & 0.80 \\
\hline P6 & 2485235.3 & 1411 & 0.88 & 2485533.3 & 1414 & 0.85 & 2485842.6 & 1426 & 0.76 \\
\hline P7 & 2496621.8 & 1418 & 0.91 & 2496796.6 & 1436 & 0.91 & 2497389.8 & 1449 & 0.83 \\
\hline P8 & 3232608.2 & 1426 & 0.88 & 3232940.2 & 1442 & 0.85 & 3233438.3 & 1459 & 0.79 \\
\hline P9 & 3621653.8 & 1464 & 0.87 & 3622041.1 & 1477 & 0.84 & 3622517.7 & 1492 & 0.77 \\
\hline P10 & 4763864.3 & 1518 & 0.94 & 4764192.3 & 1519 & 0.91 & 4764398.0 & 1523 & 0.89 \\
\hline P11 & 11942423.1 & 1541 & 0.86 & 11942470.4 & 1550 & 0.83 & 11943012.2 & 1563 & 0.80 \\
\hline P12 & 12584490.5 & 1558 & 0.89 & 12584815.3 & 1574 & 0.87 & 12585101.7 & 1593 & 0.86 \\
\hline P13 & 13390948.8 & 1572 & 0.96 & 13391049.8 & 1575 & 0.94 & 13391722.9 & 1597 & 0.89 \\
\hline P14 & 14865216.6 & 1610 & 0.98 & 14865325.9 & 1625 & 0.95 & 14865788.8 & 1636 & 0.92 \\
\hline P15 & 16218983.3 & 1679 & 0.98 & 16219142.0 & 1694 & 0.96 & 16219631.0 & 1706 & 0.87 \\
\hline \hline
\end{tabular}

Table (3): shows the output solution for the decoupled test problems using FGP, GP and FLP

\begin{tabular}{|c|c|c|c|c|c|c|c|c|c|}
\hline \multirow{2}{*}{ Prob. } & \multicolumn{3}{|c|}{ FGP } & \multicolumn{3}{|c|}{ GP } & \multicolumn{3}{|c|}{ FLP } \\
\hline & $\mathrm{Z} 1$ & $\mathrm{Z} 2$ & $\mathrm{Z3}$ & $\mathrm{Z1}$ & $\mathrm{Z} 2$ & $\mathrm{Z3}$ & $\mathrm{Z1}$ & $\mathrm{Z} 2$ & $\mathrm{Z3}$ \\
\hline P1 & 394412.8 & 1380 & 0.84 & 394694.5 & 1381 & 0.74 & 394957.0 & 1404 & 0.75 \\
\hline $\mathrm{P} 2$ & 409382.3 & 1380 & 0.73 & 409757.3 & 1382 & 0.72 & 409938.1 & 1410 & 0.70 \\
\hline P3 & 512937.4 & 1394 & 0.79 & 513005.9 & 1402 & 0.71 & 513565.0 & 1412 & 0.65 \\
\hline P4 & 600719.5 & 1392 & 0.79 & 601100.3 & 1405 & 0.78 & 601605.9 & 1406 & 0.78 \\
\hline P5 & 760428.8 & 1409 & 0.85 & 760818.2 & 1422 & 0.81 & 761318.1 & 1447 & 0.74 \\
\hline P6 & 2545593.6 & 1414 & 0.86 & 2545852.7 & 1423 & 0.80 & 2546125.8 & 1456 & 0.72 \\
\hline P7 & 2568008.5 & 1438 & 0.87 & 2568115.4 & 1437 & 0.90 & 2568165.2 & 1459 & 0.76 \\
\hline P8 & 3321844.7 & 1458 & 0.87 & 3321936.9 & 1450 & 0.79 & 3322047.3 & 1470 & 0.77 \\
\hline P9 & 3727716.3 & 1465 & 0.82 & 3728027.0 & 1492 & 0.76 & 3728370.6 & 1511 & 0.68 \\
\hline P10 & 4898422.4 & 1549 & 0.90 & 4898755.9 & 1534 & 0.89 & 4899114.6 & 1547 & 0.88 \\
\hline P11 & 12137846.8 & 1548 & 0.78 & 12137858.5 & 1562 & 0.75 & 12137897.7 & 1589 & 0.71 \\
\hline P12 & 12755652.6 & 1565 & 0.86 & 12755875.5 & 1587 & 0.85 & 12756027.2 & 1594 & 0.76 \\
\hline $\mathrm{P} 13$ & 13642444.9 & 1597 & 0.94 & 13642569.6 & 1588 & 0.85 & 13642825.4 & 1626 & 0.77 \\
\hline P14 & 15096551.4 & 1644 & 0.93 & 15096585.9 & 1642 & 0.96 & 15097050.6 & 1663 & 0.89 \\
\hline P15 & 16513171.2 & 1698 & 0.91 & 16513396.7 & 1711 & 0.90 & 16513770.8 & 1711 & 0.86 \\
\hline
\end{tabular}


Table (4): shows the demand fill rate\% for the integrated and decoupled test problems

\begin{tabular}{||c||c|c|c||c|c|c|}
\hline \multirow{2}{*}{ Prob. } & \multicolumn{3}{|c|}{ Integrated model } & \multicolumn{3}{c|}{ decoupled model } \\
\cline { 2 - 7 } & FGP & GP & FLP & FGP & GP & FLP \\
\hline P1 & 97.0 & 95.0 & 96.6 & 94.3 & 92.0 & 93.9 \\
\hline P2 & 93.7 & 94.4 & 91.4 & 90.7 & 90.2 & 90.0 \\
\hline P3 & 92.4 & 92.8 & 90.7 & 89.0 & 89.9 & 91.0 \\
\hline P4 & 93.1 & 91.7 & 90.4 & 89.6 & 89.6 & 87.9 \\
\hline P5 & 92.8 & 91.4 & 89.7 & 89.4 & 87.4 & 88.7 \\
\hline P6 & 96.0 & 95.2 & 96.2 & 94.5 & 90.9 & 93.0 \\
\hline P7 & 97.3 & 95.3 & 94.0 & 94.8 & 94.7 & 94.2 \\
\hline P8 & 95.6 & 94.9 & 92.7 & 92.8 & 91.7 & 91.6 \\
\hline P9 & 94.3 & 92.3 & 90.7 & 90.9 & 89.7 & 87.7 \\
\hline P10 & 92.4 & 91.3 & 92.0 & 91.0 & 88.8 & 86.5 \\
\hline P11 & 93.8 & 91.7 & 92.2 & 91.0 & 90.9 & 88.9 \\
\hline P12 & 93.3 & 92.5 & 91.6 & 92.1 & 92.6 & 92.3 \\
\hline P13 & 92.8 & 93.1 & 92.0 & 90.2 & 90.7 & 88.6 \\
\hline P14 & 93.2 & 93.6 & 93.0 & 90.3 & 90.0 & 88.1 \\
\hline P15 & 93.5 & 91.6 & 90.3 & 90.4 & 89.9 & 88.0 \\
\hline
\end{tabular}

Table 5 shows the sensitivity analysis between the integrated and decoupled models using fuzzy linear programming, goal programming and fuzzy goal programming techniques. The total cost decreasing rate is computed by [(total cost obtained by decoupled approach - total cost obtained by integrated approach)/total cost obtained by integrated approach]*100, represents the percentage of the total cost decreasing rate for the integration. On all problems, the integrated planning approach produced less cost than the decoupled one, with an average cost decrease rate of $2.43 \%$. The cost decrease from integration is mainly attributed to the change of production plan in the local improvement procedure that makes it possible to increase revenue, reduce stock out cost, and reduce fixed vehicle cost. The delivery time is decrease also for integrated approach for all problems with average $1.16 \%$ than decoupled one this means the customer satisfaction level for integrated approach is increased, and the unitization of facilities is increase with average $6.8 \%$ than decoupled one as shown in table 5.

Pervious Tables show the results of the empirical case study for that solved by using technique and demonstrate the quantity will produce in each plant and the amount of finished goods should be delivered the distribution centers (DCs) in each period.

The value of the total cost by the fuzzy goal programming is smaller than the cost from the Goal programming and fuzzy linear programming model for integrated and decoupled model. The same for the facilities utilization level is the largest value for FGP than others, also total delivery time for FGP is the best than others as shown in Table 5. The FGP obtained depends largely on the importance with which decision maker endows objectives so it gives a best 
AN INTEGRATED APPROACH FOR MULTI-OBJECTIVE PRODUCTION AND DISTRIBUTION PLANNING IN SUPPLY CHAIN MANAGEMENT

\section{El-baz and Mesalam}

solution in MODM problems

Table (5): shows sensitivity analysis between the integrated and decoupled test problems

\begin{tabular}{|c|c|c|c|c|c|c|c|c|c|}
\hline \multirow[b]{2}{*}{ 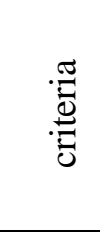 } & \multicolumn{3}{|c|}{ FGP } & \multicolumn{3}{|c|}{ GP } & \multicolumn{3}{|c|}{ FLP } \\
\hline & $\begin{array}{l}\text { Decrease } \\
\text { rate of } \\
\text { cost }\end{array}$ & $\begin{array}{c}\text { Increase } \\
\text { rate of } \\
\text { utilizatio } \\
\text { n } \\
\end{array}$ & $\begin{array}{l}\text { Decrease } \\
\text { rate of } \\
\text { delivery }\end{array}$ & $\begin{array}{c}\text { Decrease } \\
\text { rate of } \\
\text { cost }\end{array}$ & $\begin{array}{c}\text { Increase } \\
\text { rate of } \\
\text { utilizatio } \\
\text { n } \\
\end{array}$ & $\begin{array}{c}\text { Decrease } \\
\text { rate of } \\
\text { delivery }\end{array}$ & $\begin{array}{c}\text { Decrease } \\
\text { rate of } \\
\text { cost }\end{array}$ & $\begin{array}{c}\text { Increase } \\
\text { rate of } \\
\text { utilizatio } \\
\text { n } \\
\end{array}$ & $\begin{array}{l}\text { Decrease } \\
\text { rate of } \\
\text { delivery }\end{array}$ \\
\hline Prob. & $\mathrm{Z} 1$ & $\mathrm{Z} 2$ & $\mathrm{Z3}$ & $\mathrm{Z} 1$ & $\mathrm{Z} 2$ & $\mathrm{Z3}$ & $\mathrm{Z} 1$ & $\mathrm{Z} 2$ & $\mathrm{Z3}$ \\
\hline $\mathrm{P} 1$ & 2.97 & 1.77 & 1.18 & 2.99 & 0.51 & 7.50 & 2.96 & 1.08 & 3.85 \\
\hline $\mathrm{P} 2$ & 2.61 & 1.55 & 9.88 & 2.63 & 0.73 & 11.11 & 2.56 & 0.86 & 11.39 \\
\hline P3 & 2.60 & 1.75 & 1.25 & 2.53 & 1.45 & 6.58 & 2.58 & 1.29 & 7.14 \\
\hline $\mathrm{P} 4$ & 3.54 & 0.87 & 7.06 & 3.57 & 0.72 & 6.02 & 3.52 & 0.36 & 2.50 \\
\hline P5 & 2.73 & 0.50 & 8.60 & 2.73 & 0.14 & 7.95 & 2.78 & 1.05 & 7.50 \\
\hline P6 & 2.43 & 0.21 & 2.27 & 2.43 & 0.64 & 5.88 & 2.43 & 2.10 & 5.26 \\
\hline P7 & 2.86 & 1.41 & 4.40 & 2.86 & 0.07 & 1.10 & 2.83 & 0.69 & 8.43 \\
\hline P8 & 2.76 & 2.24 & 1.14 & 2.75 & 0.55 & 7.06 & 2.74 & 0.75 & 2.53 \\
\hline P9 & 2.93 & 0.07 & 5.75 & 2.93 & 1.02 & 9.52 & 2.92 & 1.27 & 11.69 \\
\hline $\mathrm{P} 10$ & 2.82 & 2.04 & 4.26 & 2.82 & 0.99 & 2.20 & 2.83 & 1.58 & 1.12 \\
\hline P11 & 1.64 & 0.45 & 9.30 & 1.64 & 0.77 & 9.64 & 1.63 & 1.66 & 11.25 \\
\hline $\mathrm{P} 12$ & 1.36 & 0.45 & 3.37 & 1.36 & 0.83 & 2.30 & 1.36 & 0.06 & 11.63 \\
\hline $\mathrm{P} 13$ & 1.88 & 1.59 & 2.08 & 1.88 & 0.83 & 9.57 & 1.88 & 1.82 & 13.48 \\
\hline P14 & 1.56 & 2.11 & 5.10 & 1.56 & 1.05 & -1.05 & 1.56 & 1.65 & 3.26 \\
\hline P15 & 1.81 & 1.13 & 7.14 & 1.81 & 1.00 & 6.25 & 1.81 & 0.29 & 1.15 \\
\hline
\end{tabular}

\section{CONCLUSIONS AND RECOMMENDATIONS}

\subsection{Conclusions}

This paper presents the solutions for a multi-objective integrated production and distribution supply chain planning problem by using lingo 11.0 software. Three objectives are considered: (1) minimization of total cost), (2) Maximize the utilization level of facilities, and (3) Minimization of total delivery time. This study used three methods for resolutions: FLP, GP, and FGP. By comparing these algorithms, it is found that the result from FGP could be well received by the decision maker. Total cost is the smallest of all the total cost items for the problem also the best level of facility utilization and the total delivery time with FGP model. The integrated planning produced lower cost and higher demand fill rate than the decoupled one.

\subsection{Recommendations}

In the planning model of this study, it is necessary to appreciate the weight relationship among each of the objectives; thus the preferences of the decision maker are extremely important. For practical management, the transaction price and manufacturing cost are not linear; transaction behavior allows discount and differential pricing, whereas manufacturing cost requires a factor as economic scale, in order to make the model realistic. For future research, there is further investigation on the problem of import and export, whose factors of influence are rather widespread and which is also one of the important issues in enterprise management. FMOP employed in this study is simply a fuzzy objective equation, and fuzzy constraint equations can be added in subsequent studies. 


\section{REFERENCES}

1. Altiparmak, F., M. Gen, L. Lin and T. Paksoy (2006). "A genetic algorithm approach for multi-objective optimization of supply chain networks" Computers and Industrial Engineering 51, pp. 196-215.

2. Alves, M.J. and J. Climaco (2007). "A review of interactive methods for multiobjective integer and mixed-integer programming approach" European Journal of Operational Research 180, pp. 99-115

3. Azaron, A., Brown, K.N., Tarim, S.A. and M. Modarres (2008). "A multi objective stochastic programming approach for supply chain design considering risk." International Journal of Production Economics 116 (1), pp. 129-138.

4. Barbarosoglu, G. and Ozgur, D. (1999) "Hierarchical design of an integrated production and 2-echelon distribution system", European Journal of Operational Research, Vol. 118, pp.464-484.

5. Bellman, R.E. and Zadeh, L.A. (1970), "Decision making in a fuzzy environment", Management Science 17B(3), 141-164

6. Cao, C., X. Gu and Z. Xin (2010). "Stochastic chance constrained mixed-integer nonlinear programming models and the solution approaches for refinery short-term crude oil scheduling problem". Applied Mathematical Modelling, 34, pp. 3231- 3243.

7. Chang, C.T. (2007). "Binary behavior of fuzzy programming with piecewise linear membership functions". IEEE Transactions on Fuzzy Systems, 15 (3), pp. 342-349

8. Chen, L. and W. Lee (2004). "Multi objective optimization of multi echelon supply chain networks with uncertain product demands and prices". Computers and Chemical Engineering 28, pp. 1131-1144.

9. Cohen, M.A. and H.L. Lee (1989). "Resource deployment analysis of global manufacturing and distribution networks." Journal of Manufacturing and Operations Management 2, pp. 81-104.

10. Fumero, F. and Vercellis, C. (1999), "Synchronized development of production, inventory, and distribution schedules". Transportation Science, 33, 330-340.

11. Gen M. and A. Syarif (2005). "Hybrid genetic algorithm for multi-time period production distribution planning". Computers and Industrial Engineering 48, pp. 799-809.

12. Gong, Q., K.K. Lai and S. Wang (2008). "Supply chain networks: Closed Jackson network models and properties". International Journal of Production Economics 113, pp.
567-574.

13. Haq, A.N., Vrat, P. and Kanda, A.(1991) “An integrated production inventory- distribution model for manufacturing of urea: a case", International Journal of Production Economics, Vol. 39, pp.39-49.

14. Hu, C.F. and S.C. Fang (1999). "Solving fuzzy inequalities with piecewise linear membership functions", IEEE Transactions on Fuzzy Systems, 7 (2), pp. 230-235

15. Lee, E.S. and Li, R.J. (1993), "Fuzzy multiple objective programming and compromise programming with Pareto optimum", Fuzzy Sets and Systems 53(2), 275-288.

16. Lee, Y.H. and Kim, S.H. (2002) "Production-distribution planning in supply chain considering capacity constraint", Computer and Industrial Engineering, Vol. 43, pp.169-190.

17. Liang, T.F. (2006). "Distribution planning decisions using interactive fuzzy multi-objective linear programming". Fuzzy Sets and Systems, 157, pp. 1303-1316.

18. Liang, T.F. (2008). "Fuzzy multi-objective production/distribution planning decisions with multi-product and multi-time period in supply chain". Computers and Industrial Engineering, 55, pp. 676-694.

19. Liang, T.F. and H.W. Cheng (2009). "Application of fuzzy sets to manufacturing/distribution planning decisions with multi-product and multi-time period in supply chains." Expert Systems with Applications 36, pp.3367-3377

20. Lin, L., M. Gen and X. Wang (2007). “A hybrid genetic algorithm for logistics network design with flexible multistage model". International Journal of Information Systems for Logistics and Management 3 (1), pp. 1-12.

21. Martin, C.H., Dent, D.C. and Eckhart, J.C, (1993). "Integrated production, distribution, inventory planning at Libbey-Owens-Ford." Interfaces, 23, 68-78.

22. Martinson, F.K. (1993), "Fuzzy vs. minmax weighted multiobjective linear programming illustrative comparisons", Decision Sciences 24(4), 809-824

23. Narasimhan, R. and S. Mahapatra (2004). "Decision models in global supply chain management". Industrial Marketing Management 33, pp. 21-27.

24. Ozdamar, L. and T. Yazgac (1997). "Capacity driven due date settings in make-to-order production systems." International Journal of Production Economics 49 (1), pp. 29-44.

25. Peidro, D., J. Mula and R. Poler (2007). "Supply chain planning under uncertainty: a 


\section{El-baz and Mesalam}

fuzzy linear programming approach". In: Fuzzy Systems Conference, 2007 FUZZ-IEEE, 2007 IEEE International, pp. 1-6.

26. Peidro, D., J. Mula, R. Poler and J.L.Verdegay (2009). "Fuzzy optimization for supply chain planning under supply, demand and process uncertainties". Fuzzy Sets and Systems 160 (18), pp. 2640-2657.

27. Pyke, D.F. and M.A. Cohen (1993). "Performance characteristics of stochastic integrated production-distribution systems". European Journal of Operational Research 68 (1), pp. 23-48.

28. Syarif, A., Y. Yun and M. Gen (2002). "Study on multi-stage logistics chain network: a spanning tree-based genetic algorithm approach." Computers and Industrial Engineering 43 (1), pp. 299-314.

29. Tanaka, H., Okuda, T. and Asai, K. (1974), "On fuzzy mathematical programming", Journal of Cybernetics 3(1), 37-46.

30. Thomas, D.J. and Griffen, P.M.,(1996) "Coordinated supply chain management." Eur. J. Oper. Res., 94, 1-15.

31. Vasant, P., R. Nagarajan and S. Yacoob (2005). "Fuzzy linear programming with vague objective coefficients in an uncertain environment". Journal of the Operational Research Society, 56, pp. 597-603

32. Yan H., Z. Yu and T.C.E. Cheng (2003). "A strategic model for supply chain design with logical constraints: formulation and solution". Computers \& Operations Research 30 (14), pp. 2135-2155.

33. Zadeh, L.A. (1965). "Fuzzy sets" Information and Control 8, pp. 338-353.

34. Zeleny, M. (1982), "Multiple Criteria Decision Making”, McGrew-Hill, New York.

35. Zimmermann, H.J. (1978), "Fuzzy programming and linear programming with several objective functions", Fuzzy Sets and Systems 1(1), 45-55.

\section{Nomenclature}

$$
\begin{aligned}
& \text { s Set of suppliers }(1,2,3 \quad \text {,S }) \\
& \text { i Set of plants }(1,2,3 \quad \text {,I }) \\
& \text { j Set of products }(1,2,3 \quad \text {, }) \\
& \mathrm{k} \quad \text { Set of distribution centers } \quad(1,2, \ldots, \mathrm{K}) \\
& 1 \text { Set of retailers }(1,2,3 \quad \text {, }) \\
& \sup _{s} \text { The capacity of supplier } s \text { for raw material } \\
& t_{s i j t} \text { The unit transportation and purchasing cost }
\end{aligned}
$$

for raw material from supplier s to plant $\mathrm{i}$ to produce product $\mathrm{j}$ in period $\mathrm{t}$.

$L_{i} \quad$ Available production capacity at plant $\mathrm{i}$ in time in any given period

$D_{i} \quad$ Available capacity of plant i.

$C_{i j} \quad$ Unit processing cost of item $\mathrm{j}$ at plant $\mathrm{i}$

$S_{i j} \quad$ Set-up cost for item $\mathrm{j}$ at plant $\mathrm{i}$

$O_{i j} \quad$ Unit processing time of item $\mathrm{j}$ at plant $\mathrm{i}$.

$U_{i j} \quad$ Set-up time for item $\mathrm{j}$ at plant $\mathrm{i}$.

$d_{i j k}^{d} \quad$ Unit transportation cost of item $\mathrm{j}$ from plant i to DCs k.

$d_{j k l}^{r} \quad$ Unit transportation cost of item $\mathrm{j}$ from DCs k to retailer 1.

$g \quad$ Fixed cost per vehicle.

$v_{k} \quad$ The annual fixed cost for operating a DC $\mathrm{k}$.

$g_{i} \quad$ The annual fixed cost for operating a plant $i$

$u_{i j k t}$ Delivery time per unit for jth product from source I to destination $\mathrm{k}$ in period $\mathrm{t}$ (hour/unit)

$B_{i j k t} \quad$ capacity per truck delivered for jth product from source $\mathrm{I}$ to destination $\mathrm{k}$ in period $\mathrm{t}$ (units)

$E_{j l t} \quad$ Demand for item $\mathrm{j}$ at retail outlet $\mathrm{l}$ in period $\mathrm{t}$

$h_{i j}^{R} \quad$ Unit holding cost per period for raw material to produce item $\mathrm{j}$ at plant $\mathrm{i}$..

$h_{i j}^{p} \quad$ Unit holding cost per period for item $\mathrm{j}$ at plant i.

$h_{j k}^{r} \quad$ Unit holding cost per period for item $\mathrm{j}$ at DCs k..

$h_{j l}^{r} \quad$ Unit holding cost per period for item $\mathrm{j}$ at retail outlet 1 .

$W_{k}^{r} \quad$ Storage capacity at DCs k.

$W_{l}^{r} \quad$ Storage capacity at retail outlet 1. 
$u_{r j} \quad$ The utilization rate of raw material $\mathrm{r}$ per unit of the product $\mathrm{j}$

$n_{j} \quad$ Space requirement rate of product $\mathrm{j}$ on a Dcs and retailer

$x_{i j t} \quad$ Amount of item $\mathrm{j}$ produced at plant $\mathrm{i}$ in period t.

$q_{i j k t}$ Amount of item $\mathrm{j}$ delivered from plant $\mathrm{i}$ to DCs $\mathrm{k}$ in period $\mathrm{t}$.

$f_{j k l t} \quad$ Amount of item $\mathrm{j}$ delivered from DCs $\mathrm{k}$ to retail outlet 1 in period $t$.

$R_{s i j t}$ The quantity of raw material shipped from supplier $\mathrm{s}$ to plant $\mathrm{i}$ to produce product $\mathrm{j}$ in period t.

$y_{i j t} \quad 1$ if plant i must be set-up for item $\mathrm{j}$ in period $t$, and 0 otherwise

$I_{i j t}^{R} \quad$ Inventory level for raw material to produce item $j$ at plant $i$ in period $t$.

$I_{i j t}^{p} \quad$ Inventory level for item $\mathrm{j}$ at plant $\mathrm{i}$ in period t.

$I_{j k t}^{d} \quad$ Inventory level for item $\mathrm{j}$ at DCs $\mathrm{k}$ in period $t$

$I_{j l t}^{r} \quad$ Inventory level for item $\mathrm{j}$ at retail outlet $\mathrm{l}$ in period t.

$z_{i k t}^{d} \quad$ Number of vehicles required for delivering from plant $\mathrm{i}$ to $\mathrm{DCs} \mathrm{k}$ in period $\mathrm{t}$.

$z_{k l t}^{r} \quad$ Number of vehicles required for delivering from DCs $k$ to retail outlet $l$ in $t$ 